\title{
Major QTLs for Trunk Height and Correlated Agronomic Traits Provide Insights into Multiple Trait Integration in Oil Palm Breeding
}

\author{
Chee-Keng Teh ${ }^{1,2, * \mathbb{C}}$, Ai-Ling Ong $\left.{ }^{1,2} \mathbb{(}\right)$, Sean Mayes ${ }^{3} \mathbb{(}$, Festo Massawe ${ }^{2} \mathbb{D}$ and \\ David Ross Appleton ${ }^{1}$ \\ 1 Biotechnology \& Breeding Department, Sime Darby Plantation R\&D Centre, \\ Serdang 43400, Selangor State, Malaysia; ong.ailing.sdtc@simedarbyplantation.com (A.-L.O.); \\ david.ross.appleton@simedarbyplantation.com (D.R.A.) \\ 2 School of Biosciences, University of Nottingham Malaysia, Semenyih 43500, Selangor State, Malaysia; \\ festo.massawe@nottingham.edu.my \\ 3 School of Biosciences, University of Nottingham, Sutton Bonington Campus, Leicestershire LE12 5RD, UK; \\ Sean.Mayes@nottingham.ac.uk \\ * Correspondence: teh.chee.keng@simedarbyplantation.com
}

Received: 7 May 2020; Accepted: 16 June 2020; Published: 21 July 2020

\begin{abstract}
Superior oil yield is always the top priority of the oil palm industry. Short trunk height (THT) and compactness traits have become increasingly important to improve harvesting efficiency since the industry started to suffer yield losses due to labor shortages. Breeding populations with low THT and short frond length (FL) are actually available, such as Dumpy AVROS pisifera (DAV) and Gunung Melayu dura (GM). However, multiple trait stacking still remains a challenge for oil palm breeding, which usually requires 12-20 years to complete a breeding cycle. In this study, yield and height increment in the GM $\times$ GM (GM-3341) and the GM × DAV (GM-DAV-3461) crossing programs were evaluated and palms with good yield and smaller height increment were identified. In the GM-3341 family, non-linear THT growth between THT_2008 (seven years old) and THT_2014 (13 years old) was revealed by a moderate correlation, suggesting that inter-palm competition becomes increasingly important. In total, 19 quantitative trait loci (QTLs) for THT_2008 (8), oil per palm (O/P) (7) and FL (4) were localized on the GM-3341 linkage map, with an average mapping interval of 2.01 cM. Three major QTLs for THT_2008, O/P and FL are co-located on chromosome 11 and reflect the correlation of THT_2008 with O/P and FL. Multiple trait selection for high O/P and low THT (based on the cumulative effects of positive alleles per trait) identified one palm from 100 palms, but with a large starting population of 1000-1500 seedling per cross, this low frequency could be easily compensated for during breeding selection.
\end{abstract}

Keywords: compact palms; marker-assisted selection; Elaeis guineensis; linkage maps; dwarfism

\section{Introduction}

Oil palm (Elaeis guineensis Jacq.) is a major source of vegetable oils and fats, contributing 35\% of global vegetable oil production [1]. Per hectare of cropland, oil palm is able to yield 10 times more oil per year than any other temperate oil crop, which leads to oil palm cultivation being one of the most efficient agricultural land uses in humid tropical environments [2]. This also explains why only $7 \%$ of total global oilseed-harvested land is occupied by oil palms [3] yet $\sim 35 \%$ of the global trade is in palm oil. To sustain long-term profit, enormous efforts have been put into improving oil yield per unit area, which involves two main components, i.e., fresh fruit bunch (FFB) production and oil-to-bunch ratio $(\mathrm{O} / \mathrm{B})$. 
In recent years, an acute labor shortage in Malaysia has become a major problem for collecting FFB and loose fruit in the field. Foreign labor represents over $70 \%$ of the total 491,339 workforce of oil palm plantations in Malaysia, which reflects their high dependency on migrants who mainly come from Indonesia, Bangladesh, the Philippines, Thailand and Myanmar [4]. In addition, foreign workers are increasingly choosing to work in oil palm plantations in their home countries for similar or higher wages. This has contributed to stagnant oil yield in Malaysia, which leads to suboptimal estate management, even though high-yielding commercial seeds are available in the country. For example, Sarawak alone incurred losses of up to US\$240 million per year in uncollected FFB because of labor shortages ranging from $15 \%$ to $20 \%$ across plantations [5]. Several mechanization approaches to harvest FFB and to collect loose fruit have been tested, but their commercial applicability is still restricted mainly due to the non-uniform palm architecture and topography of estates. Hence, the oil palm industry is keen to integrate oil yield traits and secondary vegetative traits, such as reduced trunk height and increased bunch stalk length [6] through selective breeding for better harvesting efficiency. Compact palms are a typical example. By retaining equivalent levels of inter-palm competition, the short rachis trait allows up to 180 palms per hectare, which is higher than the standard densities (138-143 palms per hectare) [7]. Improvements in yield per area, however, can only be fully realized with an increase in labor supply and/or increased levels of mechanization. Thus, the integration of slow height increment into compact palms is crucial to reduce the additional demand for labor and to facilitate mechanization.

One of the important genetic resources for reduced height increment is a self-pollinated family, Deli dumpy E206, which has been found to be uniformly short, indicating that the trait is highly heritable [8]. The family was crossed into many breeding programs, especially in Southeast Asia. In oil palm, the mesocarp oil content is partly determined by the presence/thickness of non-productive kernel shell in the fruit. To achieve 30\% more oil, the commercial thin-shelled tenera are produced from crosses between thick-shelled dura and shell-less pisifera (usually female sterile). Hence, Deli dura with $75 \%$ dumpy ancestry $\times$ commercial AVROS pisifera produced a comparable oil yield to the dura $\times$ pisifera $(\mathrm{DxP})$ control, while retaining lower trunk height growth due to the dumpy character [9]. Breeders from the Golden Hope and Highlands Research Unit (now under the Sime Darby Plantation) began exploiting this material differently. They introgressed the current pollen source, which is derived from AVROS pisifera and used very widely in Malaysia, into a new origin including 25\% dumpy ancestry, termed dumpy AVROS, and hybridized these with normal Deli dura to generate commercial tenera palms with shorter trunk height increment [10]. Also, the company adopted the Gunung Melayu dura (GM), which originated from the Deli and was selected for its low height increment and high mesocarp oil content. No significant difference in trunk height between GM $\times$ AVROS pisifera and other Deli dura $\times$ AVROS pisifera was observed [11]. However, to date, evaluation of the hybridization between GM and dumpy AVROS pisifera (DAV) to reduce trunk height has yet to be reported.

The breeding fitness of a cultivar may drop when introgression from non-elite sources of germplasm occurs. The phenomenon is mostly due to linkage drag of the undesirable effects (normally from the wild donor) of non-targeted genes or quantitative trait loci (QTL) linked to the targeted genes or inherited from other chromosomes during crossing. Multiple selection and backcrossing cycles with sufficient progeny are crucial to identify the individuals that break the linkage drag by recombination between the QTL and undesirable genes to recover an elite background. Breaking of unwanted linkages in perennial crops, such as oil palm, based on phenotypic selection is costly, time consuming and inaccurate for all but the simplest phenotypes. Many fruit agronomic traits of oil palm can only be measured after three years of field planting, followed by another four years of recording to complete a selection cycle. In addition, the environmental effects on polygenic/complex traits, including oil yield and trunk height (THT) are strong, which presents a great challenge to capturing the genetic effects in improved breeding materials. To address this, locating the QTL underlying these traits has become increasingly important. The objectives of this study include: (1) to evaluate the trait variation in reduced trunk height increment between a short-trunk maternal GM $\times$ GM population and its tenera progeny $(\mathrm{GM} \times \mathrm{DAV}),(2)$ QTL mapping for THT and THT-correlated agronomic traits in a GM $\times \mathrm{GM}$ 
population using a high-density OP200K genotyping array [12] and simple sequence repeats (SSRs), and (3) consolidating the QTL for selected traits and marker-assisted selection (MAS) to accelerate reduced height breeding programs with better trait predictability.

\section{Materials and Methods}

\subsection{Plant Materials and DNA Preparation}

A full-sib dura family, namely, GM-3341 ( $n=113$ palms) was obtained from a cross between GM-Parent1 and GM-Parent2. To determine variation in the THT trait, a progeny test family, i.e., GM-DAV-3461 tenera ( $n=70$ palms) derived from the common GM-Parent2 dura and DAV-Parent1 pisifera was selected and compared. Both GM-3341 and GM-DAV-3461 families were planted in 2001 in a randomized complete block design (RCBD) at a density of 148 palms per hectare in the East Estate (PT132 trial, 10 replicates per family) and the North Estate (PT138 trial, 5 replicates per family) of the Sime Darby Plantation on Carey Island, Malaysia. A total of 76 commercial DxP palms derived from an admixed parentage of Deli dura $\times$ AVROS pisifera were planted as a control in each trial. The control planted in the PT132 trial and PT138 trial were named DxP control (GM) and DxP control (GM-DAV), respectively. The estates generally share similar annual temperatures and rainfall. For linkage analyses, a total of 113 palms of the GM-3341 family were sampled at unopen frond 0 for DNA extraction. Total genomic DNA was isolated from $0.1 \mathrm{~g}$ of the leaf tissue using the DNAeasy Plant Mini Kit (Qiagen, Hilden, Germany). The DNA quality was visualized on a $0.8 \%$ agarose gel and quantified using the Nanodrop 2000 (NanoDrop Technologies, Wilmington, DE, USA). The DNA samples were stored at $-20{ }^{\circ} \mathrm{C}$ in a freezer for subsequent genotyping.

\subsection{Trait Recording and Statistical Analyses}

In oil palm breeding (and research) programs, the industry standard is followed, which usually involve the planting of controlled crosses in RCBD in two locations. Crosses are extensively recorded for certain traits. For example, bunch yield for every bunch (usually one bunch per month) for several years, while others are more time intensive (such as bunch analysis, where a minimum of 3 per palm is standard) or have been deemed of less importance (height increment is one of these). Overall, this tends to reflect the ease of data collection as opposed to the importance of the trait for the breeding program [13]. In this study, yield recording was started when both trials reached three years old. Both the number of bunches (BNO) and average bunch weight (BWT) were recorded to generate 4-year averages for FFB (from 2004 to 2008). At least three bunches per palm were analyzed for O/B and other bunch components according to the industry standard [14] with modifications [15]. The total oil per palm $(\mathrm{O} / \mathrm{P})$ was then calculated from the multiplication of the 4-year average FFB and average O/B. For the THT trait, the distance from the ground to the 41st frond was measured in 2008 (as THT_2008) and 2014 (as THT_2014) using an extendable ruler. At the same time, other vegetative traits were also measured based on industry standard methods [16]. A total of 16 traits (Table 1) were compiled for standard descriptive statistics; trait values between 1.5 and 3 times the interquartile range were identified as outliers and removed. Presence of low THT and short frond length (FL) were determined separately in the GM-3341 family at the PT132 trial and the GM-DAV-3461 family at the PT138 trial by comparing them to their respective DxP controls using a two-sample $T$ test at $p=0.05$ threshold. A Pearson correlation analysis of the 16 traits in the GM-3341 family was also performed at the $p=0.05$ threshold. All statistical tests were done in the Minitab ${ }^{\circledR} 17$ program [17] and box plots were generated in $\mathrm{R}$. 
Table 1. Pearson correlation of trunk height traits, frond length and oil yield-related traits of the GM-3341 family.

\begin{tabular}{cccc}
\hline Trait & Trait Abbreviation & THT_2008 & THT_2014 \\
\hline Fresh fruit bunch & FFB/kg & $0.423^{*}$ & $0.242^{*}$ \\
Bunch number & BNO & $0.364^{*}$ & 0.119 \\
Bunch weight & BWT & $0.248^{*}$ & 0.156 \\
Fruit-to-bunch ratio & F/B & -0.055 & -0.015 \\
Mean fruit weight & MFW & -0.068 & 0.107 \\
Mesocarp-to-fruit ratio & M/F & -0.150 & 0.103 \\
Shell-to-fruit ratio & S/F & 0.156 & -0.153 \\
Kernel-to-fruit ratio & K/F & 0.033 & 0.043 \\
Oil-to-dry mesocarp ratio & O/DM & 0.237 & 0.216 \\
Oil-to-wet mesocarp ratio & O/WM & -0.038 & -0.042 \\
Oil-to-bunch ratio & O/B & 0.126 & 0.069 \\
Kernel-to-bunch ratio & K/B & 0.081 & -0.005 \\
Total oil per palm & O/P & $0.294 *$ & 0.165 \\
Frond length & FL & $0.270 *$ & $0.301 *$ \\
Trunk height in 2008 & THT_2008 & NA & $0.595 *$ \\
Trunk height in 2014 & THT_2014 & NA & NA \\
\hline
\end{tabular}

* Significant correlation at the $p=0.05$ threshold; NA—not applicable.

\subsection{DNA Marker Genotyping}

A tenera palm, namely, Progeny palm 5002 derived from D4-93/76 (Deli dura) $\times 2 / 2311$ (EKONA pisifera) was whole-genome sequenced with 30X coverage using the Roche 454 Titanium FLX platform. From the reference genome, a total of 11,653 SSRs were discovered and primers designed. The SSR amplification conditions with fluorescent-labeled M13-tailed forward primers [18] were optimized for each of the primer pairs and followed by genotype scoring using an Applied Biosystems 3730xl DNA Analyser (Applied Biosystems, Carlsbad, CA, USA). The SSR primers formed a multiallelic marker framework. Furthermore, the OP200K Infinium array (Illumina, San Diego, CA, USA) based on 59 breeding origins of oil palms [12] was applied to the population. Only the markers with heterozygous genotypes in at least one of the parents of the GM-3341 family were defined as informative and were used to genotype the mapping population.

\subsection{Construction of Linkage Maps}

The GM-3341 family, which is defined as a cross-pollinator (CP) population, was deployed as a mapping population. A full-density $\mathrm{GM} \times \mathrm{GM}$ linkage map was constructed using Lep-MAP3 $[19,20]$ for large number of SNPs, which is applicable to outbred families, such as oil palm, based on the maximum likelihood method. Marker quality was checked under the Filtering module. Informative SNPs with $>5 \%$ of missing data and/or identical genotype segregation were removed. Subsequently, the Separate Chromosomes module was used for binning the assayed SNPs in each parent based on the optimized logarithm of odds, to the base 10 (LOD) thresholds ranging from 4 to 30 . To order the binned SNPs, the Kosambi mapping function was adopted for the conversion of recombination frequencies into map distances (in unit $\mathrm{cM}$ ). The maps of both parents were joined as one using the option "sexAveraged $=1$ ". A subset of SNPs was selected from every $5 \mathrm{cM}$ of the full-density linkage map and loaded into the Joinmap ${ }^{\circledR} 5$ program [21] for linkage mapping to enable QTL mapping analysis. In addition, a set of 67 informative SSRs were also included. The markers with segregation distortion at chi-square $p<0.001\left(^{* * *}\right)$ were removed. The selected markers were ordered based on optimized LOD thresholds (6.0-9.0) with the Kosambi map function and regression model, and the linkage map was visualized using the Mapchart 2.32 program [22]. Each LG number was identified with a chromosome of the published physical map [23]. In addition, the linked SNPs were also mapped onto the same physical map to estimate correlation between linkage (in $\mathrm{cM}$ ) and physical (in $\mathrm{Mb}$ ) positions in the genome (Tables S1 and S2), which allowed recombination estimates (in cM/Mb) 
across the pseudo-chromosomes. Finally, the average mapping interval was calculated at LG and genome-wide levels.

\subsection{Quantitative Trait Locus Mapping Analyses}

All QTL mapping analyses for THT_2008, THT_2014, O/P and FL traits were carried out using the MapQTL ${ }^{\circledR} 6$ program [24]. Initially, single marker tests using the rank sum test of Kruskal-Wallis (KW) were done at the $p=0.005$ threshold, followed by interval mapping (IM) to identify potential QTL peaks. In order to determine the genome-wide LOD threshold, permutation tests were performed with 1000 iterations at $\alpha=0.05$, but 'putative' QTLs at 1.5 below the genome-wide LOD $=4.0$ threshold were still reported. The significant QTLs detected in IM were fixed as cofactors for multiple QTL mapping (MQM) mapping. Any new QTLs detected were considered as cofactors for the next round of MQM mapping and the process were iterated until no change occurred. Then, trait variation explained by the identified QTL was determined based on MQM mapping analysis.

\subsection{Cumulative Effects of Quantitative Trait Allele Analysis}

The putative and genome-wide significant QTLs were selected to measure the marker effects for THT_2008, FL and O/P traits based on median comparison among alleles in Minitab ${ }^{\circledR} 17$ program [17]. In each QTL, the positive alleles in each trait that benefit the breeding program were defined in the GM-3341 family (107 palms after outlier removal). The alleles that decreased FL and THT_2008 values were known as positive, whereas the positive alleles for $\mathrm{O} / \mathrm{P}$ increased the trait value. Next, the total number of positive alleles across the QTLs in individual palms were plotted against each trait to determine the cumulative effects of quantitative trait alleles. The threshold number of positive alleles for each trait selection was defined based on the intersection between the mean line of a trait and the fitted line on a scatter plot. The threshold numbers of positive alleles and mean trait values were then used to perform palm selection for multiple traits on a scatter plot between traits.

\section{Results}

\subsection{Descriptive Statistics and Comparison of Traits between Families}

Sixteen traits related to oil yield, THT and FL were recorded in the GM-3341 dura family ( $n=107$ palms) and the GM-DAV-3461 tenera family ( $n=70$ palms) located in PT132 in the East Estate and PT138 in the North Estate, respectively (Table S3). A commercial DxP control was also included in each trial and served as a control for comparison of traits using a two-sample $T$ test at the $p=0.05$ threshold. After removal of the outliers, the 16 traits followed normal distributions at the $p=0.05$ threshold and the dataset was subjected to subsequent analyses. The GM-3341 family produced $19.50 \pm 5.00 \mathrm{~kg} / \mathrm{palm} /$ year of $\mathrm{O} / \mathrm{P}$, which was lower than the $26.25 \pm 7.44 \mathrm{~kg} / \mathrm{palm} /$ year produced by the GM-DAV-3461 family. Poorer average performance in both FFB $(103.37 \pm 21.21 \mathrm{~kg} /$ palm/year $)$ and O/B $(18.72 \pm 2.70 \%)$ in the GM-3341 family were the main contributors, compared to $125.90 \pm 24.49 \mathrm{~kg} /$ palm/year of average $\mathrm{FFB}$ and $20.29 \pm 3.90 \%$ of average O/B in the GM-DAV-3461 family. Shell thickness variation within tenera was measured by the shell-to-fruit ratio (S/F). As expected, the GM-3341 family had a thicker shell (average S/F $=30.97 \pm 3.24 \%$ ) than that of the GM-DAV-3461 family (average $\mathrm{S} / \mathrm{F}=15.59 \pm 2.82 \%$ ), with the GM-3341 being purely dura shell-types and the GM-DAV-3461 being purely the thinner tenera hybrid. In terms of average fruit-to-bunch ratio (F/B), the GM-3341 family and the GM-DAV-3461 recorded $63.60 \pm 4.71 \%$ and $60.45 \pm 5.63 \%$, respectively, which were within the normal range, i.e., $60-65 \%$ [13]. Trunk height and FL were measured twice, once in 2008 (as THT_2008) and also in 2014 (as THT_2014) at PT132 trial, whereas only a single measurement was done at the PT138 trial in 2008 (Table S3). The GM-3341 family at the PT132 trial with a mean THT_2008 $=145.07 \mathrm{~cm}$ and mean FL $=534.53 \mathrm{~cm}$ were significantly shorter than the DxP control, which had means for THT_2008 $=213.02 \mathrm{~cm}$ and FL $=554.83 \mathrm{~cm}$ at the $p=0.05$ threshold for both (Figure 1A,B). The same result was observed in the PT138 trial, where the 
GM-DAV-3461 family had means for THT $2008=206.37 \mathrm{~cm}$ and FL $=565.34 \mathrm{~cm}$ and were significantly shorter than the DxP control with means for THT_2008 $=266.90 \mathrm{~cm}$ and FL $=584.30 \mathrm{~cm}$ at the same $p$ threshold (Figure 1C,D).
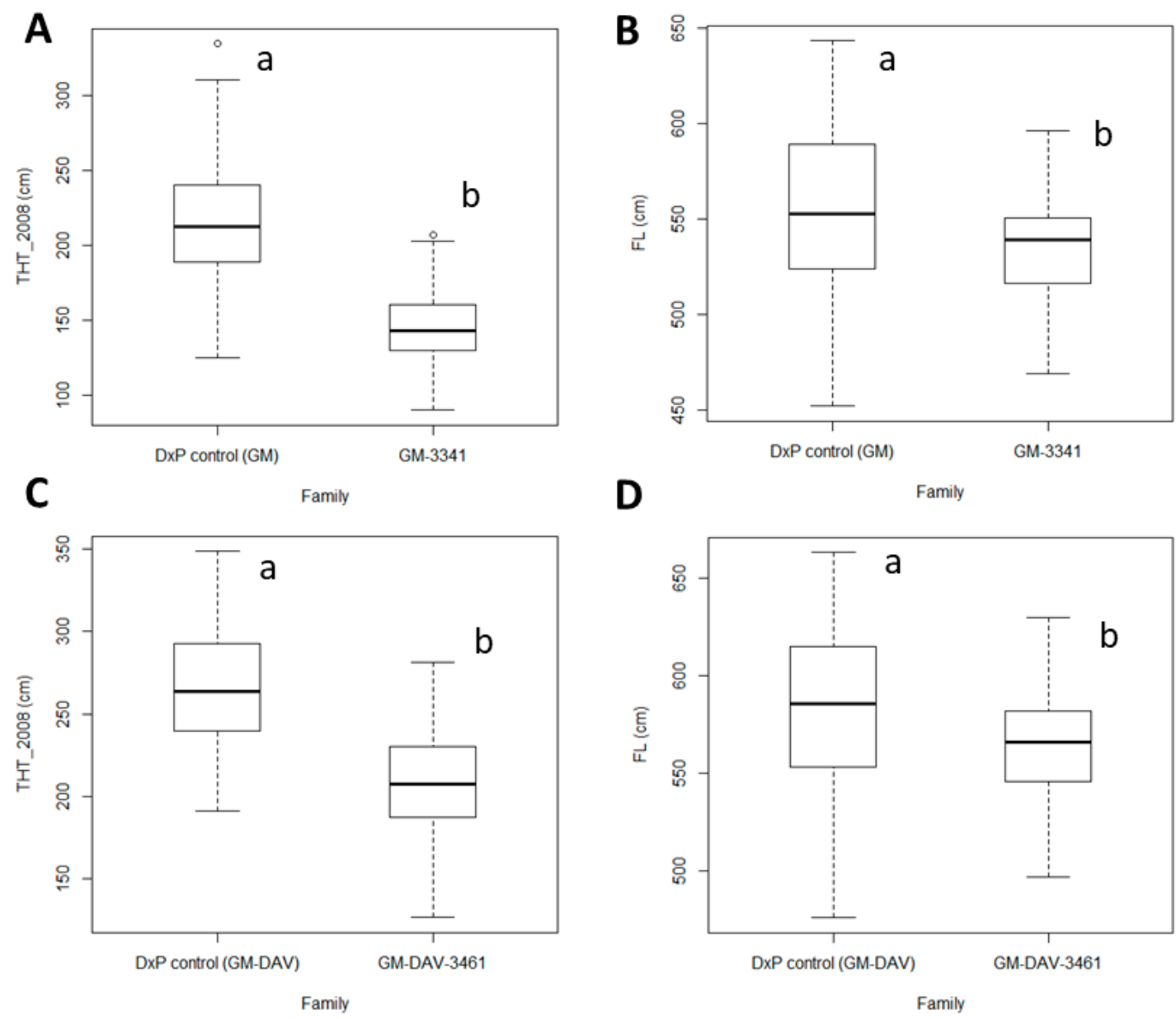

Figure 1. The boxplots represent median values, percentile 25-75 for trunk height measured in 2008 (THT_2008) and frond length (FL) between families. (A) THT_2008 comparison between the DxP control and the GM-3341 family in the PT132 trial in the East Estate; (B) FL comparison between the DxP control and the GM-3341 family in the PT132 trial in the East Estate; (C) THT_2008 comparison between the DxP control and the GM-DAV-3461 family in PT138 in the North Estate; (D) FL comparison between the DxP control and the GM-DAV-3461 family in PT138 in the North Estate. The trait comparisons were analyzed based on two-sample $t$ test at the $p=0.05$ threshold.

\subsection{Pearson Correlation among Traits}

The correlations among all the 16 traits of the GM-3341 family are illustrated in Table S4. As mentioned, $\mathrm{O} / \mathrm{P}$ is a derivative trait from multiplying $\mathrm{FFB}$ and $\mathrm{O} / \mathrm{B}$ per palm, thus significant correlations with FFB (correlation coefficient, $r=0.619 ; p=0.000)$ and $\mathrm{O} / \mathrm{B}(r=0.332 ; p=0.007$ ) were observed. The same effects applied to the component traits of FFB and O/B. Fresh fruit bunch weight significantly correlated with BNO $(r=0.824 ; p=0.000)$ and average BWT $(r=0.253 ; p=0.012)$, while $\mathrm{O} / \mathrm{B}$ significantly correlated with $\mathrm{F} / \mathrm{B}(r=0.473 ; p=0.000)$, mesocarp-to-fruit ratio $(\mathrm{M} / \mathrm{F})(r=0.490$; $p=0.000)$ and oil-to-wet mesocarp $(\mathrm{O} / \mathrm{WM})(r=0.444 ; p=0.000)$. In addition, oil palm fruitlets are mostly made up of an outer layer of mesocarp and a central nut consisting of a shell-coated kernel. Hence, each of the fruitlet components is actually a proportion of the mean fruit weight (MFW) and this was reflected in the significant correlations among MFW, S/F, M/F and the kernel-to-fruit ratio $(\mathrm{K} / \mathrm{F})$. A significant correlation was also detected between independent oil yield-related traits such as 
$\mathrm{BNO}$ with $\mathrm{F} / \mathrm{B}(r=-0.262 ; p=0.036)$. For vegetative traits, there was a correlation between FL and THT (THT_2008, $r=0.270 ; p=0.008$ and THT_2014, $r=0.301 ; p=0.009$ ) (Tables 1 and S4). Interestingly, THT recorded in 2008 and 2014 was not highly correlated $(r=0.595 ; p=0.000)$, suggesting the non-linear THT increment of oil palm over the growing cycle. THT_2008 correlated better with yield-related traits including O/P, FFB, BNO and BWT, compared to THT_2014 and FL. This is likely to be before (THT_2008) and after (THT_2014) palm-to-palm competition becomes important.

\subsection{Construction of Linkage Maps}

The GM-3341 family, as a mapping population was genotyped using 200,000 SNPs. Of these, 33,190 SNPs were considered informative for linkage mapping and were successfully binned into linkage groups (LGs) that were consistent with 16 chromosome pairs of oil palm genome $(2 \mathrm{n}=32)$. The constructed linkage map with 33,190 SNPs spanned a cumulative length of 1618.51 centiMorgan (cM) with an average mapping interval of $0.05 \mathrm{cM}$ and was termed the "full-density" map (data not shown). For QTL localization, a subset of 588 SNPs with an average mapping interval of $5 \mathrm{cM}$ were coupled with 67 informative SSRs (Tables S1 and S2) to build a linkage map with reduced density. From this, 565 markers with $\leq 5 \%$ missing data were linked as a linkage map that had a cumulative length of $1093.51 \mathrm{cM}$ and a lower average mapping interval of $2.01 \mathrm{cM}$ (Figure 2, Table 2). The number of LGs, however, increased to 17, because LG1 fragmented into two, namely, LG1a and LG1b. The marker positions between full and reduced-density linkage maps were compared and were generally in good agreement. The latter map was then adopted for estimating an average recombination rate throughout the genome, which was $1.74 \mathrm{cM} / \mathrm{Mb}$, and which ranged from $0.63 \mathrm{cM} / \mathrm{Mb}$ (LG1b) to $3.24 \mathrm{cM} / \mathrm{Mb}$ (LG10).

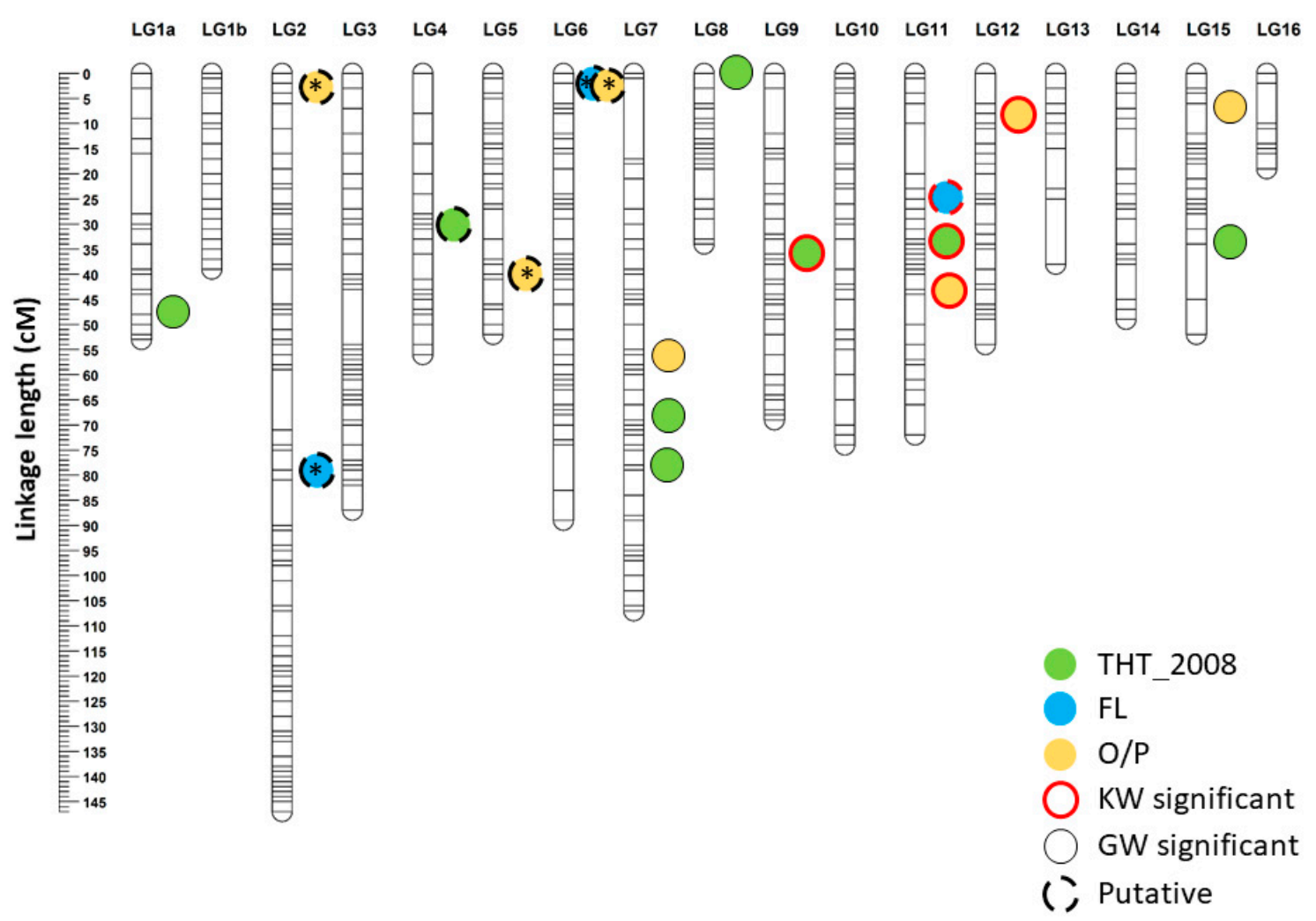

Figure 2. Distribution of quantitative trait loci (QTLs) for trunk height in 2008 (THT_2008), frond length (FL) and total oil per palm $(\mathrm{O} / \mathrm{P})$ on a linkage map of the GM-3341 family. KW significant-Kruskal-Wallis at the $p=0.005$ threshold; GW significant-genome-wide logarithm of odds, to the base $10(\mathrm{LOD})=4.0$ threshold; putative $-2.4 \leq \mathrm{LOD}<4.0$ threshold; * non-cofactor. 
Table 2. Linkage length and mapping interval across linkage groups in the GM-3341 family.

\begin{tabular}{|c|c|c|c|c|c|c|c|c|}
\hline No. & Group & $\begin{array}{c}\text { Linkage } \\
\text { Length (cM) }\end{array}$ & $\begin{array}{c}\text { No. of } \\
\text { Linked Markers }\end{array}$ & $\begin{array}{l}\text { Mapping } \\
\text { Interval (cM) }\end{array}$ & $\begin{array}{l}\text { No. of Markers in } \\
\text { the Physical Map }\end{array}$ & $\begin{array}{l}\text { Linkage Length } \\
\text { of Common } \\
\text { Markers (cM) }\end{array}$ & $\begin{array}{c}\text { Physical } \\
\text { Length (Mb) }\end{array}$ & $\begin{array}{c}\text { Average } \\
\text { Recombination } \\
\text { Rate }(\mathrm{cM} / \mathrm{Mb})\end{array}$ \\
\hline 1 & LG1a & 53.44 & 20 & 2.67 & 10 & 53.44 & 63.71 & 0.84 \\
\hline 3 & LG2 & 147.43 & 73 & 2.02 & 36 & 147.43 & 64.78 & 2.28 \\
\hline 4 & LG3 & 86.94 & 48 & 1.81 & 27 & 86.94 & 58.66 & 1.48 \\
\hline 5 & LG4 & 55.97 & 32 & 1.75 & 9 & 55.97 & 34.73 & 1.61 \\
\hline 6 & LG5 & 52.11 & 34 & 1.53 & 20 & 52.11 & 37.29 & 1.40 \\
\hline 9 & LG8 & 33.67 & 28 & 1.20 & 22 & 33.67 & 39.98 & 0.84 \\
\hline 10 & LG9 & 69.28 & 38 & 1.82 & 23 & 68.16 & 34.66 & 1.97 \\
\hline 11 & LG10 & 74.31 & 35 & 2.12 & 19 & 74.31 & 22.94 & 3.24 \\
\hline 12 & LG11 & 72.36 & 37 & 1.96 & 13 & 72.36 & 26.05 & 2.78 \\
\hline 13 & LG12 & 54.00 & 28 & 1.93 & 26 & 54.00 & 26.63 & 2.03 \\
\hline 14 & LG13 & 37.90 & 11 & 3.45 & 7 & 23.12 & 25.51 & 0.91 \\
\hline
\end{tabular}

* Sum total; ${ }^{* *}$ average value; GW-genome-wide; LG-linkage map; cM-centiMorgan; Mb-Megabase; each LG identified as a chromosome of the published genome [23].

\subsection{Mapping of QTLs for THT, FL and O/P Traits}

The QTL mapping for THT and correlated traits started with single marker testing on 655 linked markers using the ranking sum test of KW. A total of 49 significant markers were detected to be effecting THT_2008 (30 markers), THT_2014 (1 marker), FL (13 markers) and O/P (5 markers) at the $p=0.005$ threshold (Table S5). Subsequently, the lower-density linkage map of the GM-3341 family was used to conduct IM. The detected IM-based QTLs were fixed as cofactors for MQM analyses. LOD $=4.0$ was set as the genome-wide significance threshold based on permutation tests with 1000 iterations at $\alpha=0.05$, whereas the QTLs within $2.5 \leq$ LOD $<4.0$ were termed "putative". First of all, no significant QTL for THT_2014 was found in IM and MQM. As shown in Figure 2, however, genome-wide significant QTLs for THT_2008 were detected on LG1a, LG7, LG8, LG9, LG11 and LG15, explaining 7.4-17.0\% of the trait variation each (Figure 2, Table 3). Another putative QTL for the same trait was located on LG4 with $4.3 \%$ of the variation explained. As for FL, four putative QTLs on LG2 and LG6 and LG11 that explained 10.2-16.5\% of the variation were found. Three of the QTLs on LG2 (rs795951455) and LG6 (rs795993306 and ss1810567844) emerged as non-cofactor peaks when rs795990373 on LG11 was fixed as a cofactor. Similarly, by fixing the four genome-wide significant QTLs for O/P residing at $56.03 \mathrm{cM}$ on LG7, $43.79 \mathrm{cM}$ on LG11, $34.73 \mathrm{cM}$ on LG12 and $16.25 \mathrm{cM}$ on LG15 as cofactors, three putative QTLs emerged on LG2, LG6 and LG5. The O/P variation explained by these QTLs ranged from $6.0-28.5 \%$.

\subsection{Cumulative Effects of Quantitative Trait Allele Analysis}

In this analysis, we adopted 16, 9 and 6 positive alleles for THT_2008, O/P and FL, respectively. Only THT_2008 and O/P traits fit well into quadratic relationships between the number of the positive QTL alleles and trait variation, but in antagonistic directions (Figure $3 \mathrm{~A}-\mathrm{C}$ ). The palms carrying more than 13 positive alleles for THT_2008 trait were mainly shorter than the population mean $=145.07 \mathrm{~cm}$, whereas those with more than 7 positive alleles for $\mathrm{O} / \mathrm{P}$ trait mainly yielded higher than the population mean $=19.50 \mathrm{~kg} / \mathrm{palm} /$ year. Hence, the number of positive alleles for respective THT_2008 and O/P were used for multiple trait selection (Figure 3D). We found that $77 \%$ and $86 \%$ of the selected palms had shorter THT and higher O/P than the population mean, suggesting that the single trait selection method was effective. For multiple trait selection, by contrast, only one palm in the GM3341 family with low THT and high O/P (the orange dot shown in Figure 3D) was identified using the QTL markers. 
Table 3. Multiple QTL mapping and Kruskal-Wallis test for trunk height recorded in 2008 (THT_2008), frond length (FL) and total oil per palm (O/P) traits in the GM-3341 family.

\begin{tabular}{|c|c|c|c|c|c|c|}
\hline Trait & Linkage Group & Cofactor & Peak LOD & $\begin{array}{c}\text { Peak Position } \\
\text { (cM) }\end{array}$ & $\begin{array}{l}\text { Trait Variation } \\
\text { Explained (\%) }\end{array}$ & KW \\
\hline \multirow{8}{*}{ THT_2008 } & $1 \mathrm{a}$ & rs795987799 & 4.55 & 48.04 & 7.6 & \multirow{8}{*}{$\begin{array}{l}* * * * * \\
* * * *\end{array}$} \\
\hline & 4 & rs795956088 & 2.67 & 30.22 & 4.3 & \\
\hline & 7 & rs796035893 & 6.65 & 68.67 & 11.7 & \\
\hline & 7 & ss1810504935 & 6.79 & 78.32 & 12.0 & \\
\hline & 8 & rs795967221 & 5.02 & 0.00 & 8.5 & \\
\hline & 9 & rs796032489 & 4.42 & 35.56 & 7.4 & \\
\hline & 11 & ss1810516343 & 9.11 & 33.55 & 17.0 & \\
\hline & 15 & rs795995560 & 5.99 & 33.79 & 10.4 & \\
\hline \multirow{7}{*}{$\mathrm{O} / \mathrm{P}$} & 2 & $\mathrm{DA} 290^{\mathrm{NC}}$ & 3.74 & 81.14 & 7.6 & \multirow{7}{*}{$\begin{array}{l}* * * * \\
* * * *\end{array}$} \\
\hline & 5 & rs796007949 NC & 2.88 & 39.55 & 6.0 & \\
\hline & 6 & DA358 NC & 3.02 & 88.89 & 6.3 & \\
\hline & 7 & ss1810302303 & 4.09 & 56.03 & 10.9 & \\
\hline & 11 & rs796015770 & 4.56 & 43.79 & 12.4 & \\
\hline & 12 & rs796017329 & 8.13 & 34.73 & 25.2 & \\
\hline & 15 & rs795992318 & 8.92 & 16.25 & 28.5 & \\
\hline \multirow{4}{*}{ FL } & 2 & rs795951455 NC & 2.69 & 79.40 & 10.2 & \multirow[b]{4}{*}{$* * * * * * *$} \\
\hline & 6 & rs795993306 NC & 3.11 & 2.26 & 11.7 & \\
\hline & 6 & ss1810567844 NC & 3.11 & 2.38 & 11.7 & \\
\hline & 11 & rs795990373 & 3.73 & 24.55 & 16.5 & \\
\hline
\end{tabular}

THT_2008-Trunk height in 2008, THT_2014-Trunk height in 2014, O/P-Total oil per palm, ${ }^{\text {NC }}$ non-cofactor, cM-centiMorgan, KW-Kruskal-Wallis statistics, ${ }^{* * * *} 0.005$ significance level, ${ }^{* * * * *} 0.001$ significance level, ******* 0.0005 significance level.

A
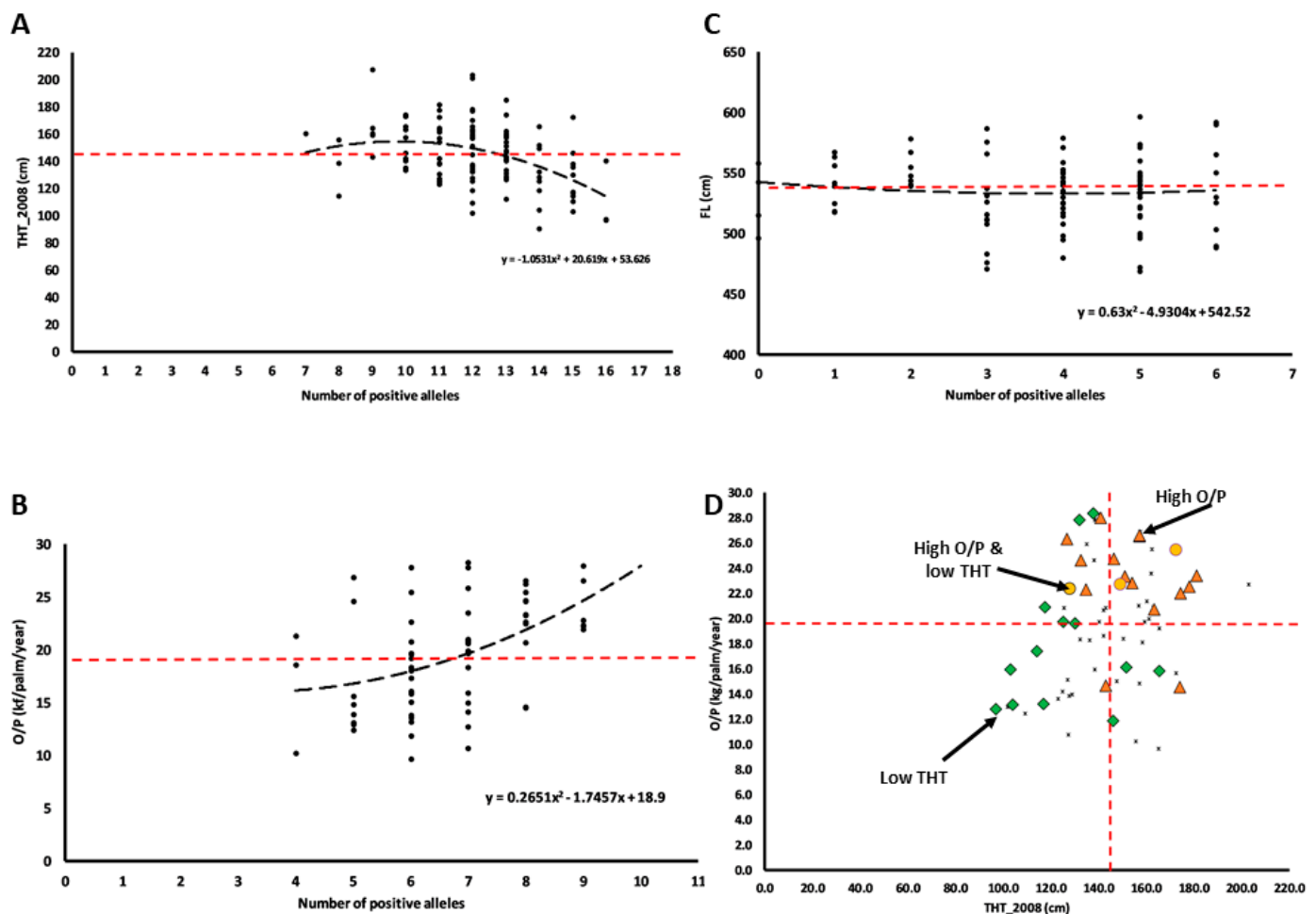

Figure 3. Cumulative effects of quantitative trait alleles for (A) THT_2008, (B) O/P, (C) FL traits, and (D) the application for selection of THT_2008 and O/P traits in the GM-3341 Family. Red dotted line-mean THT_2008 $(145.07 \mathrm{~cm})$, mean O/P (19.50 kg/palm/ year) and mean FL (534.53 cm); orange dot-High O/P and low THT_2008, red triangle-High O/P, green diamond-Low THT_2008; multiple trait selection in Figure 3D based on threshold numbers of positive alleles for THT_2008 = 13 and for $\mathrm{O} / \mathrm{P}=7$. 


\section{Discussion}

Oil palm breeding in Southeast Asia predominantly started with the Deli dura, which is believed to be derived from four palms planted in the Bogor Botanical Garden, Indonesia in 1848 [25,26]. The Deli dura were subsequently distributed to various breeding programs, each of which stressed different selection approaches over generations and caused separation between subpopulations, which are known as "breeding populations of restricted origin" (BPRO) [27]. However, these breeding programs still share the same overall objective, that is, superior oil yield, which has been achieved by different selection for traits. In addition, understanding the co-dominant inheritance of the shell thickness gene [28] also paved the way for exploitation of the superior oil content of the thin-shelled tenera, which was commercially produced from hybridization between thick-shelled Deli dura and shell-less AVROS pisifera. At the beginning of the 1960s, planters in the Southeast Asia region successfully realized a $30 \%$ increment in oil yield per hectare as tenera planting materials replaced the original Deli $d u r a$ materials $[13,29]$. In this study, we also observed a 34.6\% O/P increment from the GM-3314 dura family $(19.50 \pm 5.00 \mathrm{~kg} / \mathrm{palm} /$ year$)$ to the DAV-GM-3461 tenera family (26.25 $\pm 7.44 \mathrm{~kg} / \mathrm{palm} /$ year) (Table S3).

Nevertheless, the oil palm industry in Malaysia started to experience labor shortages, particularly for FFB and loose fruit collection, around a decade ago and the problem is escalating. Hence, the breeding objective of superior oil yield is being expanded to include traits, such as low THT and compactness to improve harvest and management efficiency. In this study, low THT and short frond length within the GM-3341 family and its half-sib GM-DAV-3461 family was found to be heritable from GM dura and DAV pisifera (Figure 1). This finding supports the idea that both traits can actually be improved through hybridization between GM and DAV origins to produce short or even compact tenera palms, compared to using a single genetic donor of GM origin as reported earlier [11]. The robustness of trait data was verified based on significant correlations between the derivative traits and associated component traits of the GM-3341 family at the $p=0.05$ threshold (Table S4). Meaningful biological interpretation was also performed based on the correlations between independent traits. For example, an inverse correlation between $\mathrm{BNO}$ and $\mathrm{F} / \mathrm{B}(r=-0.262 ; p=0.036)$ is likely to be related to the pollination ability of weevils (Elaeidobius kamerunicus), which is reflected in the number of insects per receptive female inflorescence per hectare [30]. Decline in "pollination force"' can happen if many receptive female inflorescences are developed in an area with a fixed population of weevils. In such scenarios, the palms still can produce more BNO, but a smaller number of flowers on these female inflorescences were pollinated to form fruitlets, leading to lower FFB. Bunches with more than $60 \%$ F/B are considered normal [30,31], so, both the GM-3341 family and the GM-DAV-3461 family did not encounter a fruit set problem.

In the GM-3341 family, trunk growth was found to be non-linear across different ages based on a moderate correlation between THT_2008 (seven years after planting) and THT_2014 (13 years after planting) $(r=0.595 ; p=0.000)$ (Table 1$)$. This finding agrees with previous studies of trunk growth in oil palm, which are generally affected by three main factors, i.e., palm age, genotype and environmental conditions (such as agronomic practices and soil types) [32]. In the first 3 years, trunk growth is usually negligible [33] and then becomes significant at six years onwards [34]. Furthermore, many studies also reported that THT does increase with planting density, but the effect only becomes observable at 9 years after planting, which is when the canopy starts to overlap $[35,36]$. The mature palms tend to grow taller to compete for sunlight, so the genotype effect on THT is no longer as clear at that stage. Taller palms will also capture more sunlight, so small differences in height may lead to large differences in FFB. This may have complicated the QTL detection for THT_2014 in IM and MQM. Palm-to-palm competition might affect the yield mechanism in these palms as well, based on the missing correlations between THT_2014 and yield traits (O/P, FFB, BNO and BWT). It is worth noting that the yield recording in this study was conducted around 7 years after planting, so is unlikely to include the effects of competition between palms.

Oil palm breeders have attempted to stack superior O/P, low THT and short FL to produce compact palms. In most breeding programs, multiple trait integration becomes a real challenge when 
desirable traits are antagonistic to each other. Such a phenomenon is common in oil palm breeding for high-yielding, compact and low THT palms. We noticed that THT_2008 was significantly correlated to $\mathrm{O} / \mathrm{P}(r=0.294)$ and FL $(r=0.270)$, which is undesirable from a breeding perspective (Tables 1 and S4). These correlations seem to be biologically sensible in that vigorous vegetative growth of fronds and trunk height help to capture more sunlight for photosynthesis. However, it is not simple as that. In Arabidopsis, the relationship between leaf area growth and plant biomass was reported to be non-linear; it depends on how carbon assimilates produced from photosynthesis are partitioned into new leaf area, roots, reproduction and respiration [37]. In fact, the same findings for oil palm were also reported three decades ago $[38,39]$. Photosynthesis rate increases in response to sink demand in the crop. Extra assimilates will only be allocated to FFB production (effectively oil yield) after the demand for vegetative growth and maintenance is satisfied [34]. Thus, the moderate correlation between THT_2008 and O/P raises the possibility of selecting palms that buck this trend and have a higher proportion of dry matter in fruit bunches. However, when dealing with multiple complex traits, breaking linkage drag in perennial oil palm through conventional breeding methods will always be hindered by small progeny size with 16-96 palms per cross. With a planting density of 136-146 palms per hectare, the field evaluation of a large number of progenies is too costly and labor intensive-this is where MAS can help.

By using the OP200K genotyping array [12], the GM family with 33,190 linked markers was more genetically diverse than the reported commercial Deli $\times$ AVROS family with 27,890 linked markers [40], which presumably reflects the effect of breeding selection pressure in the latter population. High-density linkage maps are known to be a powerful way to improve physical genome assemblies. For instance, a further $311 \mathrm{Mb}$ of scaffolds were successfully anchored to the pseudo-chromosomes of oil palm based on the Deli $\times$ AVROS linkage map [40]. The genome of melon (Cucumis melo L.) double haploid line DL92 was also extended with $354.8 \mathrm{Mb}$ of sequence using a linkage map with an average mapping interval of $1.99 \mathrm{cM}$ [41]. Nonetheless, QTL localization on a high-density linkage map using the MapQTL ${ }^{\circledR} 6$ program is always constrained by insufficient degrees of freedom to accommodate many markers (typically $>600$ ) due to uninformative segregation types in cross-pollinating (CP) populations [24], which is common in oil palm. Hence, we only selected markers at around $5 \mathrm{cM}$ apart to construct a lower-density linkage map with 565 linked markers that spanned a cumulative length of $1093.51 \mathrm{cM}$ with an average mapping interval of $2.01 \mathrm{cM}$, but with good genome coverage (Figure 2, Table 2). The marker order in both maps were highly correlated but the mapping interval was smaller than $5 \mathrm{cM}$, as expected when a degree of conflicting data is removed. Inflated map length and orientation errors are likely to be reduced after removing some markers with incorrect SNP calling. The genome-wide recombination rate of $1.74 \mathrm{cM} / \mathrm{mb}$ calculated in the GM genome was close to the Deli $\times$ AVROS genome $(1.8 \mathrm{cM} / \mathrm{Mb})[40]$ and the date palm genome (Phoenix dactylifera) $(1.9 \mathrm{cM} / \mathrm{Mb})[42]$, suggesting this is a reasonable range for palm species.

For QTL mapping, double recombination should rarely occur in the lower-density linkage map, which is still much denser than the $10 \mathrm{cM}$ threshold [43]. Linkage group 1 fragmented into LG1a and LG1b in the lower-density map. In fact, this did not restrict the analysis, because all LGs are traceable to the 16 homologous chromosomes of the reference genome [23]. We preferred MQM analysis because it is a single dimensional search over the genome to test a single segregating QTL as in IM, while simultaneously fitting the selected cofactor, under both the null-hypothesis $\left(\mathrm{H}_{0}\right)$ and the alternative hypothesis $\left(\mathrm{H}_{1}\right)$. With this approach, the cofactors can reduce the residual variance, therefore, if a QTL explains a large proportion of the total variance, the linked markers used as cofactors in subsequent MQM analyses can significantly improve the power for identifying new segregating QTLs [24]. This method thus enabled detection of new QTLs for THT_2008, O/P and FL traits after fixing the major QTLs on LG9, LG11 and LG12 as cofactors (Figure 2). Interestingly, we found that ss1810516343 as the major QTL for THT_2018 was closely flanked by putative QTL locus rs795990373 for FL and genome-wide significant rs796015770 for O/P on LG9. This marker arrangement strongly reflects the correlation of THT_2008 with O/P and FL, suggesting a possible pleotropic effect. In fact, 
the effects of reduced height on increased yield are seen in other crops. A good example is wheat, where the famous Reduced Height (Rht) gene has a pleotropic effect, decreasing plant height and increasing grain yield [44]; the subsequent discovery of $R h t-B 1 b$ and $R h t-D 1 b$ successfully improved seed yield by $5-10 \%$ with a $20 \%$ stem height reduction [45].

This study provides initial QTL locations to enable identification of causal genes, particularly for THT and O/P traits. For this purpose, the QTLs that were genome-wide and KW significant should be given the highest priority (Table 2). The GM-based QTLs for THT identified in this study are in different locations from previous studies based on Deli dura $\times$ DAV origin [46] and Dura $\times$ Ghana origin [47], which reveals the possible effects of different genes or gene paralogues across the genomes derived from different origins. Consequently, the application of the current set of QTL genes for height may remain origin specific, unless the genetic causality is fully understood. To prepare for MAS in the GM origin, the cumulative effects of quantitative trait alleles for THT_2008, O/P and FL were used as a model to determine the effects of different numbers of positive alleles for the best selection response. The results show that single trait selections for THT_2008 and FL based on 13 and seven positive alleles were promising for the former but not for FL (Figure 3). The FL variation did not significantly deviate from the population mean $(534.53 \mathrm{~cm})$ regardless of how many positive alleles were carried; thus, the trait was omitted for multiple locus selection. Using the same thresholds, we identified only $1 \%$ of the GM3341 family with low THT and high O/P to be selected for progeny testing with DAV pisifera palms. In a multiple trait integration program in oil palm, this probability of success makes it is close to "impossible" to break the linkage drag, especially if the current breeding approach of using a limited family size (usually not more than 96 palms assessed per cross) remains unchanged. Before field planting, breeders can plant all 1000-1500 seedlings per cross in the nursery and select for the best 100 palms using the markers derived from this research, for field planting for the next breeding cycle. A $1 \%$ selection would provide 10-15 palms containing the desired alleles and multiple bunches of the same cross would provide large enough families to field select for additional variation beyond the selected loci.

\section{Conclusions}

The reduced THT and FL traits from GM and DAV origins have been determined, and show great potential for selective breeding. Further understanding of the correlations between agronomic traits and the effects of the cumulative positive alleles of QTLs pave the way for breeders to conduct multiple trait integration through MAS programs, particularly to produce high-yielding short or compact oil palms. With a $1 \%$ probability of breaking linkage drag, future trials need to be saturated with elite palms selected from a large starting population. However, non-linear THT growth across developmental stages should also be taken cautiously, depending on the breeding objectives.

Supplementary Materials: The following are available online at http://www.mdpi.com/2073-4425/11/7/826/s1, Table S1: The 655 selected markers (588 SNPs and 67 SSRs) for linkage map construction. Table S2: Sequences of 67 SSR primer pairs. Table S3: Descriptive statistics of oil yield, frond length and trunk height traits. Table S4: Person correlation among the 16 traits of the GM-3341 family. Table S5: Kruskal-Wallis analyses of trait-affecting markers. All SNPs of the OP200K genotyping array have been deposited in dbSNP under the handle of SDTC_BB with NCBI submitted SNP (ss) accession numbers of 1810069240-1810592638.

Author Contributions: Conceptualization, C.-K.T., S.M. and F.M.; investigation, C.-K.T., A.-L.O. and S.M.; manuscript writing, C.-K.T. and A.-L.O.; writing-review and editing, S.M., F.M. and D.R.A.; supervision, F.M., S.M. and D.A.; funding acquisition, D.R.A. All authors have read and agreed to the published version of the manuscript.

Funding: This research was fully supported by internal grants from Sime Darby Plantation, Malaysia.

Acknowledgments: We would like to acknowledge the contribution of the Oil Palm Breeding Section, Sime Darby Plantation R\&D Centre for conducting the breeding trials and providing the oil palm materials. We also would like to thank the Sime Darby Plantation, Malaysia for funding and the University of Nottingham Malaysia for the PhD fee scholarship to C.-K.T. and A.-L.O.

Conflicts of Interest: The authors declare no conflict of interest. 


\section{References}

1. OECD/FAO. OECD-FAO Agricultural Outlook 2019-2028; OECD Publishing: Paris, France; Food and Agriculture Organization of the United Nations: Rome, Italy, 2019.

2. Sayer, J.; Ghazoul, J.; Nelson, P.; Klintuni Boedhihartono, A. Oil palm expansion transforms tropical landscapes and livehoods. Glob. Food Secur. 2012, 1, 114-119. [CrossRef]

3. ISTA Mielke. Oil World; ISTA Mielke: Hamburg, Germany, 2018.

4. Hanim, A. Help for palm oil industry. Star 2012. Available online: https://www.thestar.com.my/business/ business-news/2012/05/15/help-for-palm-oil-industry (accessed on 5 May 2020).

5. Diana, R. Manpower still a problem in oil palm industry. Star 2013. Available online: https: //www.thestar.com.my/news/community/2013/07/24/manpower-still-a-problem-more-locals-needed-tomitigate-labour-shortage-in-oil-palm-industry/ (accessed on 5 May 2020).

6. Le Guan, V.; Ouattara, S.; Jacquemard, J.C. Oil palm selection with a view to easier harvesting. Initial results. Oléagineux 1990, 45, 523-531.

7. Barcelos, E.; Rios, S.d.A.; Cunha, R.N.V.; Lopes, R.; Motoike, S.Y.; Babiychuk, E.; Skirycz, A.; Kushnir, S. Oil palm natural diversity and the potential for yield improvement. Front. Plant Sci. 2015, 6, 190. [CrossRef] [PubMed]

8. Jagoe, R.B. The dumpy oil palm Malay. Agric. J. 1952, 35, 12.

9. Soh, A.C.; Vanialingam, T.; Taniputra, B.; Pamin, K. Derivatives of the dumpy palm-Some experimental results. Plant 1981, 57, 227-239.

10. Nair, K.P.P. Oil Palm (Elaeis guineensis Jacquin). In The Agronomy and Economy of Important Tree Crops of the Developing World; Nair, K.P.P., Ed.; Elsevier: London, UK, 2010; pp. 209-236. [CrossRef]

11. Lee, C.H.; Pang, T.Y. Breeding for short height increment in oil palm. In Proceedings of the International Symposium of Oil Palm Genetic Resources and Utilization, Kuala Lumpur, Malaysia, 8-10 June 2000; p. 12.

12. Kwong, Q.B.; Teh, C.K.; Ong, A.L.; Heng, H.Y.; Lee, H.L.; Mohaimi, M.; Low, J.Z.; Sukganah, A.; Chew, F.T.; Mayes, S.; et al. Development and validation of a high-density SNP genotyping array for african oil palm. Mol. Plant 2016, 9, 1132-1141. [CrossRef]

13. Corley, R.H.V.; Tinker, P.B. Selection and breeding. In The Oil Palm, 3rd ed.; Blackwell: Oxford, UK, 2003; pp. 133-187.

14. Blaak, G.; Sparnaaij, L.D.; Menendez, T. Methods of bunch analysis. In Breeding and Inheritance in the Oil Palm (Elaeis Guineensis Jacq.) Part II; Springer: Berlin, Germany, 1963; Volume 4, pp. 146-155.

15. Rao, V.; Soh, A.C.; Corley, R.H.V.; Lee, C.H.; Rajanaidu, N.; Tan, Y.P.; Chin, C.W.; Lim, K.C.; Tan, S.T.; Lee, T.P.; et al. A critical reexamination of the method of bunch analysis in oil palm breeding. Palm Oil Res. Inst. Malays. Occ. Pap. 1983, 9, 1-28.

16. Corley, R.H.V.; Hardon, J.J.; Tan, G.Y. Analysis of growth of the oil palm (Elaeis guineensis Jacq.) I. Estimation of growth parameters and application in breeding. Euphytica 1971, 20, 307-315. [CrossRef]

17. Minitab, Inc. Minitab17; Computer Software; Minitab, Inc.: State College, PA, USA, 2016.

18. Blair, M.W.; Hedetale, V.; McCouch, S.R. Fluorescent-labeled microsatellite panels useful for detecting allelic diversity in cultivated rice (Oryza sativa L.). Theor. Appl. Genet. 2002, 105, 449-457. [CrossRef]

19. Rastas, P.; Paulin, L.; Hanski, I.; Lehtonen, R.; Auvinen, P. Lep-MAP: Fast and accurate linkage map construction for large SNP datasets. Bioinformatics 2013, 29, 3128-3134. [CrossRef]

20. Rastas, P. Lep-MAP3: Robust linkage mapping even for low-coverage whole genome sequencing data. Bioinformatics 2017, 33, 3726-3732. [CrossRef]

21. Van Ooijen, J.W. Software for the Calculation of Genetic Linkage Maps in Experimental Populations of Diploid Species; Kyazma, B.V.: Wageningen, The Netherlands, 2018.

22. Voorrips, R.E. MapChart: Software for the graphical presentation of linkage maps and QTLs. J. Hered. 2002, 93, 77-78. [CrossRef]

23. Singh, R.; Ong-Abdullah, M.; Low, E.T.L.; Manaf, M.A.A.; Rosli, R.; Nookiah, R.; Ooi, L.C.L.; Ooi, S.E.; Chan, K.L.; Halim, M.A.; et al. Oil palm genome sequence reveals divergence of interfertile species in Old and New worlds. Nature 2013, 500, 335-339. [CrossRef] 
24. Van Ooijen, J.W. MapQTL 6, Software for the Mapping of Quantitative Trait Loci in Experimental Populations of Diploid Species; Kyazma, B.V.: Wageningen, The Netherlands, 2009.

25. Pamin, K.A. A hundred and fifty years of oil palm in Indonesia: From the Bogor Botanical Garden to the industry. In Proceedings of the International Oil Palm Conference 'Commodity of the Past, Today and the Future', Bali, Indonesia, 23-25 September 1998; pp. 3-23.

26. Kushairi, A.; Rajanaidu, N. Breeding populations, seed production and nursery management. In Advances in Oil Palm Research; Basiron, Y., Jalani, B.S., Chan, K.W., Eds.; Malaysian Palm Oil Board: Kuala Lumpur, Malaysia, 2000; Volume 1, pp. 39-98.

27. Rosenquist, E.A. The genetic base of oil palm breeding populations. In Proceedings of the International Workshop on Oil Palm Germplasm and Ultilization, Bangi, Malaysia, 26-27 March 1985; pp. 27-56.

28. Beirnaert, A.; Vanderweyen, R. Contribution à l'étude génétique et biométrique des variétiés d'Elaeis guineensis Jacq. Publ. Inst. Nat. Etude Agron. Congo Belge Ser. Sci. 1941, 3, 95-110.

29. Hardon, J.J.; Corley, R.H.V.; Lee, C.H. Breeding and Selecting the Oil Palm; Academic Press: London, UK, 1987; pp. 63-81.

30. Mohd Basri, W.; Norman, K. Role and effectiveness of Elaeidobius kamerunicus, Thrips hawaiiensis and Pyroderces sp. in pollination of mature oil palm in Peninsular Malaysia. J. Oil Palm Res. 1997, 9, 1-16.

31. Cik Mohd Rizuan, Z.A.; Noor Hisham, H.; Samsudin, A. Role of pollinating weevil (Elaeidobius kamerunicus), seasonal effect and its relation to fruit set in oil palm area of FELDA. In Proceedings of the PIPOC 2013 Conference, Kuala Lumpur, Malaysia, 19-21 November 2013.

32. Henson, I.E. Measuring and modelling oil palm trunk growth. Oil Palm Bull. 2006, 52, 1-24.

33. Jacquemard, J.C. Contribution to the study of the height growth of the stems of Elaeis guineensis Jacq. Study of the L2T $\times$ D10D cross. Oléagineux 1979, 34, 492-497.

34. Corley, R.H.V.; Tinker, P.B. Growth, flowring and yield. In The Oil Palm, 4th ed.; Blackwell Science Ltd.: Oxford, UK, 2016; pp. 89-134.

35. Kwan, B.K.W. The effect of planting density on the first fifteen years of growth and yield of oil palm in Sabah. Tech. Bull. 1994, 11, 26.

36. Henson, I.E.; Mohd Tayeb, D. Physiological analysis of an oil palm density trial on a peat soil. J. Oil Palm Res. 2003, 15, 1-27.

37. Weraduwage, S.M.; Chen, J.; Anozie, F.C.; Morales, A.; Weise, S.E.; Sharkey, T.D. The relationship between leaf area growth and biomass accumulation in Arabidopsis thaliana. Front. Plant Sci. 2015, 6. [CrossRef]

38. Henson, I.E. Photosynthesis and source-sink relationship in oil palm. Trans. Malays. Soc. Plant Physiol. 1990, $1,165-171$.

39. Henson, I.E. Age-related changes in stomatal and photosynthetic characteristics of leaves of oil palm (Elaeis guineensis Jacq.). Elaeis 1991, 4, 51-59.

40. Ong, A.-L.; Teh, C.-K.; Kwong, Q.-B.; Tangaya, P.; Appleton, D.R.; Massawe, F.; Mayes, S. Linkage-based genome assembly improvement of oil palm (Elaeis guineensis). Sci. Rep. 2019, 9, 6619. [CrossRef]

41. Argyris, J.M.; Ruiz-Herrera, A.; Madriz-Masis, P.; Sanseverino, W.; Morata, J.; Pujol, M.; Ramos-Onsins, S.E.; Garcia-Mas, J. Use of targeted SNP selection for an improved anchoring of the melon (Cucumis melo L.) scaffold genome assembly. BMC Genom. 2015, 16, 4. [CrossRef]

42. Mathew, L.S.; Spannagl, M.; Al-Malki, A.; George, B.; Torres, M.F.; Al-Dous, E.K.; Al-Azwani, E.K.; Hussein, E.; Mathew, S.; Mayer, K.F.X.; et al. A first genetic map of date palm (Phoenix dactylifera) reveals long-range genome structure conservation in the palms. BMC Genom. 2014, 15, 285. [CrossRef]

43. Xu, Z.; Zou, F.; Vision, T.J. Improving quantitative trait loci mapping resolution in experimental crosses by the use of genotypically selected samples. Genetics 2005, 170, 401-408. [CrossRef]

44. Balyan, H.S.; Singh, O. Pleiotropic effects of GA-insensitive Rht Genes on grain yield and its component characters in wheat. Cereal Res. Commun. 1994, 22, 195-200.

45. Jobson, E.M.; Johnston, R.E.; Oiestad, A.J.; Martin, J.M.; Giroux, M.J. The Impact of the wheat Rht-B1b semi-dwarfing allele on photosynthesis and seed development under field conditions. Front. Plant Sci. 2019, 10. [CrossRef] 
46. Pootakham, W.; Jomchai, N.; Ruang-areerate, P.; Shearman, J.R.; Sonthirod, C.; Sangsrakru, D.; Tragoonrung, S.; Tangphatsornruang, S. Genome-wide SNP discovery and identification of QTL associated with agronomic traits in oil palm using genotyping-by-sequencing (GBS). Genomics 2015, 105, 288-295. [CrossRef]

47. Lee, M.; Xia, J.H.; Zou, Z.; Ye, J.; Rahmadsyah; Alfiko, Y.; Jin, J.; Lieando, J.V.; Purnamasari, M.I.; Lim, C.H.; et al. A consensus linkage map of oil palm and a major QTL for stem height. Sci. Rep. 2015, 5, 8232. [CrossRef]

(C) 2020 by the authors. Licensee MDPI, Basel, Switzerland. This article is an open access article distributed under the terms and conditions of the Creative Commons Attribution (CC BY) license (http://creativecommons.org/licenses/by/4.0/). 